\title{
Recombinant Human TSH-Assisted Radioactive Iodine Remnant Ablation Achieves Short-Term Clinical Recurrence Rates Similar to Those of Traditional Thyroid Hormone Withdrawal
}

\author{
R. Michael Tuttle ${ }^{1}$, Matvey Brokhin ${ }^{2}$, Gal Omry $^{1}$, Andrew J. Martorella ${ }^{1}$, Steven M. Larson ${ }^{3}$, Ravinder K. Grewal ${ }^{3}$, \\ Martin Fleisher ${ }^{4}$, and Richard J. Robbins ${ }^{5}$ \\ ${ }^{I}$ Division of Endocrinology, Memorial Sloan-Kettering Cancer Center, New York, New York; ${ }^{2}$ Division of Endocrinology, Geisinger \\ Medical Center, Danville, Pennsylvania; ${ }^{3}$ Division of Nuclear Medicine, Memorial Sloan-Kettering Cancer Center, New York, New York; \\ ${ }^{4}$ Clinical Chemistry, Memorial Sloan-Kettering Cancer Center, New York, New York; and ${ }^{5}$ Department of Medicine, Methodist Hospital, \\ Houston, Texas
}

Recent studies have confirmed that radioactive iodine therapy after recombinant human TSH (rhTSH) stimulation effectively ablates the normal thyroid remnant. However, no published study has determined the effectiveness of rhTSH preparations on the important endpoint of disease recurrence. Methods: Disease recurrence was retrospectively assessed a median of $2.5 \mathrm{y}$ after radioiodine remnant ablation (RRA) in 394 consecutive thyroid cancer patients (93\% papillary, $71 \%$ female, $47 \pm 15$ y old [mean $\pm \mathrm{SD}$ ], median ${ }^{131}$ I dose of $3,996 \mathrm{MBq}$ [108 mCi]). Results: Similar rates of clinically evident disease recurrence (4\% rhTSH vs. $7 \%$ thyroid hormone withdrawal [THW], $P=$ not statistically significant) and residual thyroid bed uptake without other evidence of persistent disease (4\% rhTSH vs. $7 \%$ THW, $P=$ not statistically significant) were seen in the 320 patients undergoing rhTSH-assisted RRA and the 74 patients prepared for RRA by THW. When the definition of no clinical evidence of disease included a suppressed thyroglobulin level of less than $1 \mathrm{ng} /$ $\mathrm{mL}$ and a stimulated thyroglobulin level of less than $2 \mathrm{ng} / \mathrm{mL}$, rhTSH-assisted RRA was associated with significantly higher rates of no clinical evidence of disease $(74 \% \mathrm{rhTSH}$ vs. $55 \%$ THW, $P=0.02$ ) and significantly lower rates of persistent disease (19\% rhTSH vs. $32 \%$ THW, $P=0.02$ ) than was RRA after THW. Patients selected for rhTSH-assisted RRA were older (48 \pm 15 vs. $44 \pm 15 \mathrm{y}, P=0.03$ ) and received a slightly higher administered activity of ${ }^{131} \mathrm{I}$ (median, 4,033 MBq [109 $\mathrm{mCi}$ ] vs. 3,811 $\mathrm{MBq}$ [103 $\mathrm{mCi}$ ], $P=0.01$ ) but did not differ with respect to sex, histology, disease stage, or mean time to recurrence (19 \pm 9 mo for rhTSH vs. $20 \pm 16$ mo for THW). Conclusion: rhTSHassisted RRA is associated with rates of clinically evident disease recurrence and persistent uptake in the thyroid bed that are similar to those for traditional THW.

Received Dec. 13, 2007; revision accepted Jan. 30, 2008.

For correspondence or reprints contact: Matvey Brokhin, Endocrinology, MC 13-41, Geisinger Medical Center, 100 N. Academy Ave., Danville, PA 17822.

E-mail: mbrokhin@hotmail.com

COPYRIGHT @ 2008 by the Society of Nuclear Medicine, Inc.
Key Words: radioactive iodine; remnant ablation; thyroid cancer; rhTSH; thyrogen

J Nucl Med 2008; 49:764-770

DOI: 10.2967/jnumed.107.049072

$\mathbf{R}$ adioiodine remnant ablation (RRA) is given after total thyroidectomy in an effort to destroy both the normal thyroid remnant and microscopic residual disease (1-3). Although there is no consensus on the optimal activity of ${ }^{131}$ I to be administered, administered activities ranging from 2,275 to $5,550 \mathrm{MBq}(75-150 \mathrm{mCi})$ result in successful ablation of the thyroid remnant in at least $85 \%$ of patients (4).

The rationale for RRA includes decreasing the risk of clinical tumor recurrence (5) and improving the sensitivity and specificity of follow-up testing with periodic serum thyroglobulin measurement and radioiodine scanning $(6,7)$. Historically, RRA has been performed after withholding levothyroxine replacement for 4 or more weeks to increase endogenous thyroid-stimulating hormone (TSH) production to promote ${ }^{13 \mathrm{I}} \mathrm{I}$ radioiodine uptake and retention in the remaining thyroid cells (8). However, thyroid hormone withdrawal (THW) usually results in a wide range of physical and psychologic side effects associated with clinical hypothyroidism. This, in turn, often results in significant morbidity, safety risks, productivity impairment, and a major negative effect on patients' overall quality of life $(4,9,10)$.

Recombinant human TSH (thyrotropin- $\alpha$, or rhTSH [Thyrogen; Genzyme Corp.]) has been developed as a source of exogenous TSH and was approved for diagnostic use in patients with differentiated thyroid cancer by the U.S. Food and Drug Administration in December 1998 (6). Diagnostic studies using rhTSH for surveillance of thyroid cancer patients have found this method of preparation to be 
as sensitive and specific for the detection of recurrent or persistent disease as are studies done after THW (11-13).

More recently, rhTSH was approved as an adjunct for RRA, first in Europe (2005) and then in the United States (2007). In Europe, the approval was for ablation of thyroid remnant tissue in low-risk patients in combination with $3,700 \mathrm{MBq}(100 \mathrm{mCi})$ of radioactive iodine. In the United States, the approval was for RRA of thyroid tissue remnants in patients who had undergone a near-total or total thyroidectomy for well-differentiated thyroid cancer and who do not have evidence of metastatic thyroid cancer. Although no specific administered activity was recommended by the U.S. Food and Drug Administration, it did note that 3,700 $\mathrm{MBq}(100 \mathrm{mCi}) \pm 10 \%$ was used in the prospective randomized trial that was the primary basis for approval (14). The more rapid whole-body clearance of radioactive iodine after rhTSH, compared with THW, results in a lower total-body radiation exposure for a given administered activity $(1,6)$.

Despite several recent studies showing that RRA after rhTSH stimulation effectively achieves the surrogate endpoint of complete ablation of the normal thyroid remnant on follow-up whole-body radioiodine scanning (DxWBS) while reducing serum thyroglobulin to undetectable levels $(1,2,14-16)$, no published study has determined the effectiveness of the rhTSH preparation on the primary endpoint of disease recurrence. Because the rhTSH preparation was shown to be comparable to THW for diagnostic studies and, to a smaller extent, for RRA purposes, we hypothesized that clinically evident recurrence rates after RRA would be similar between patients who were prepared by THW and patients who were prepared by rhTSH. In this study, we retrospectively determined clinical outcomes after RRA in patients with differentiated thyroid cancer after preparation with either traditional THW or rhTSH.

\section{MATERIALS AND METHODS}

\section{Subjects}

Three hundred ninety-four consecutive patients with differentiated thyroid cancer treated with RRA at Memorial SloanKettering Cancer Center (MSKCC) between 1997 and 2005 were identified and included in our study. Of these, 74 had RRA after THW (group 1) and 320 after rhTSH preparation without wholebody dosimetry (group 2). The choice of preparation for RRA (THW vs. rhTSH) was a clinical decision made by the patient and the treating physician as previously described (2). All thyroid remnant ablations, regardless of the method of preparation, were done by the same nuclear medicine group following a standard clinical protocol. Before RRA, each patient had a near-total or total thyroidectomy. All study patients followed a low-iodine diet for least $1 \mathrm{wk}$ before ablation. Follow-up clinical status and serum thyroglobulin values were available for all patients. In addition, 291 patients underwent DxWBS 12-18 mo after the RRA at our medical center.

\section{Radioactive lodine Remnant Ablation}

After total thyroidectomy, patients in group 1 (THW) were administered triiodothyronine for $2-4 \mathrm{wk}$ and then withdrawn from it for $2 \mathrm{wk}$ before the RRA. Their stimulated TSH and thyroglobulin levels were drawn on the day that the tracer dose of 74-148 MBq (2-4 mCi) of ${ }^{123}$ I radioiodine was administered (day 1). As per our standard clinical protocol (2), a TSH level of more than $25 \mathrm{mIU} / \mathrm{L}$ was required before RRA. The patients returned on day 2 for a diagnostic whole-body scan with subsequent administration of the ablative dose of ${ }^{131} \mathrm{I}$.

Patients in group 2 (rhTSH) were administered levothyroxine immediately after surgery and continued to take the levothyroxine throughout the RRA procedure. One to 3 mo after surgery, group 2 patients received $0.9 \mathrm{mg}$ of rhTSH intramuscularly on the mornings of days 1 and 2, followed by a tracer dose of 74-148 MBq (2$4 \mathrm{mCi}$ ) of ${ }^{123} \mathrm{I}$ on the afternoon of day 2 . They returned on the morning of day 3 for a diagnostic whole-body scan and an ablative dose of ${ }^{131} \mathrm{I}$. A posttherapy scan was obtained for each patient 5-7 $\mathrm{d}$ after administration of the ablative dose of ${ }^{131} \mathrm{I}$ (Fig. 1).

All patients were provided with information on low-iodine diets and encouraged to adhere to them carefully. The administered activity of ${ }^{131}$ I chosen for ablation was based on the recommendations of a thyroid cancer tumor board consisting of adult and pediatric endocrinologists, nuclear medicine physicians, thyroid surgeons, and oncologists. The activity selected was based on the clinical features of the patient, the histologic findings, intraoperative findings, risk of recurrence, and results of diagnostic whole-body scanning. In general, an administered activity of $2,775-3,700 \mathrm{MBq}$ (75-100 $\mathrm{mCi}$ ) was given for intrathyroidal papillary thyroid cancers, $3,700-5,550 \mathrm{MBq}(100-150 \mathrm{mCi})$ if cervical lymph nodes were involved with tumor, and more than 5,550 $\mathrm{MBq}(150 \mathrm{mCi})$ if disease was locally aggressive or known distant metastases were present.

\section{Follow-up}

After RRA, all patients began taking suppressive doses of levothyroxine, with a goal TSH level of $0.1-0.4 \mathrm{mIU} / \mathrm{L}$ in most patients. The first 6-mo follow-up evaluation included physical examination and thyroid function tests (including TSH and free thyroxine) and suppressed thyroglobulin assessment. The 12- to 18-mo follow-up evaluation usually included thyroid function tests, suppressed and rhTSH-stimulated thyroglobulin assessment, and follow-up rhTSH-stimulated DxWBS (185 MBq [5 mCi] of $\left.{ }^{131} \mathrm{I}\right)$ at our medical center according to the methods described in earlier studies (2). Other diagnostic studies such as neck ultrasonography,

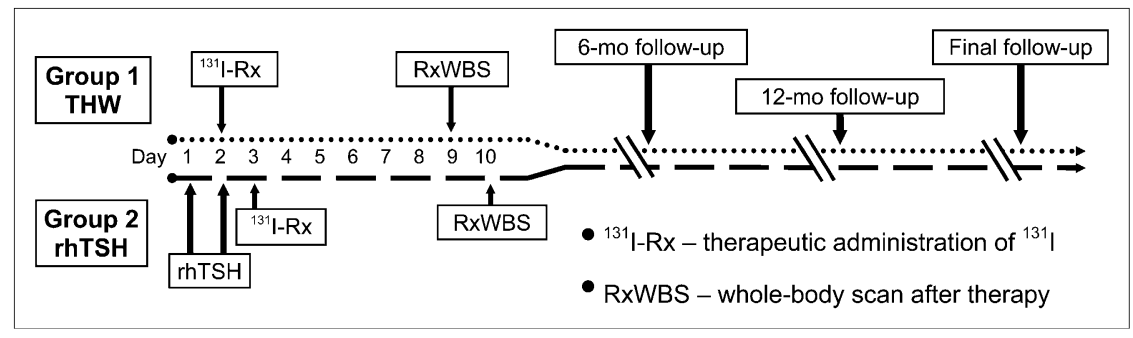

FIGURE 1. Study time line. 
TABLE 1

Patient and Tumor Characteristics

\begin{tabular}{|c|c|c|c|}
\hline Characteristic & $\begin{array}{c}\text { THW } \\
(n=74)\end{array}$ & $\begin{array}{c}\text { rhTSH } \\
(n=320)\end{array}$ & $P$ \\
\hline $\begin{array}{l}\text { Mean age }( \pm S D) \\
\text { at diagnosis }(y)\end{array}$ & $44.0 \pm 15.0$ & $48.3 \pm 15.0$ & 0.03 \\
\hline \multicolumn{4}{|l|}{ Sex (\%) } \\
\hline Female & 67.6 & 72.2 & 0.43 \\
\hline Male & 32.4 & 27.8 & \\
\hline \multicolumn{4}{|l|}{ Cancer histology (\%) } \\
\hline Papillary & 58.1 & 65.6 & 0.14 \\
\hline Follicular & 1.4 & 2.2 & \\
\hline $\begin{array}{c}\text { Follicular variant } \\
\text { of papillary }\end{array}$ & 39.2 & 26.3 & \\
\hline Hurthle & 1.4 & 3.8 & \\
\hline Poorly differentiated & - & 2.2 & \\
\hline \multicolumn{4}{|l|}{ TNM classification (\%) } \\
\hline TX & 1.4 & - & 0.06 \\
\hline $\mathrm{T} 1$ & 37.8 & 26.3 & \\
\hline $\mathrm{T} 2$ & 21.6 & 19.7 & \\
\hline T3 & 33.8 & 45.9 & \\
\hline $\mathrm{T} 4 \mathrm{a}$ & 5.4 & 6.6 & \\
\hline $\mathrm{T} 4 \mathrm{~b}$ & - & 1.6 & \\
\hline $\mathrm{NX}$ & - & 0.3 & 0.50 \\
\hline NO & 58.1 & 48.8 & \\
\hline $\mathrm{N} 1 \mathrm{a}$ & 17.6 & 23.1 & \\
\hline N1b & 24.3 & 27.8 & \\
\hline MO & 93.2 & 94.4 & 0.71 \\
\hline M1 & 6.8 & 5.6 & \\
\hline \multicolumn{4}{|l|}{ Disease stage (AJCC6) } \\
\hline 1 & 59.5 & 52.8 & 0.85 \\
\hline II & 6.8 & 8.1 & \\
\hline III & 17.6 & 21.6 & \\
\hline IVa & 12.2 & 13.4 & \\
\hline $\mathrm{IVb}$ & - & 0.9 & \\
\hline IVc & 4.1 & 3.1 & \\
\hline
\end{tabular}

cross-sectional imaging, and ${ }^{18}$ F-FDG PET were done at the discretion of the treating physician on the basis of the clinical features of each case. After the first year, patients were seen at 6to 9-mo intervals as part of routine follow-up care.

Time variables analyzed included both time to detection of recurrence in patients who had recurrent disease and time to last follow-up in patients with no clinical evidence of disease (NCED), persistent disease, or thyroid bed uptake only.

\section{Treatment Outcomes}

We categorized 4 treatment outcomes. The first was NCED, defined as a negative rhTSH DxWBS 12-18 mo after RRA, all suppressed thyroglobulin levels less than $2 \mathrm{ng} / \mathrm{mL}$, no other clinical evidence of recurrence, and a rhTSH-stimulated thyroglobulin level of less than $10 \mathrm{ng} / \mathrm{mL}$. The second outcome, clinical recurrence, was detection of new metastatic sites by any modality after a period of NCED. Most of these sites were lymph nodes found by neck ultrasound or physical examination 1-2 y after the initial ablation. The third outcome, persistent disease, was a suppressed thyroglobulin level greater than or equal to $2 \mathrm{ng} / \mathrm{mL}$ at least $1 \mathrm{y}$ after ablation, a stimulated thyroglobulin level greater than or equal to $10 \mathrm{ng} / \mathrm{mL}$ at least $1 \mathrm{y}$ after ablation, persistent known structural disease (detected by ultrasound, PET, MRI, or other modalities), discovery of a new metastasis within 6 mo of the ablation (by examination, cross-sectional imaging, or func-
TABLE 2

Nuclear Medicine Parameters and Follow-up Time

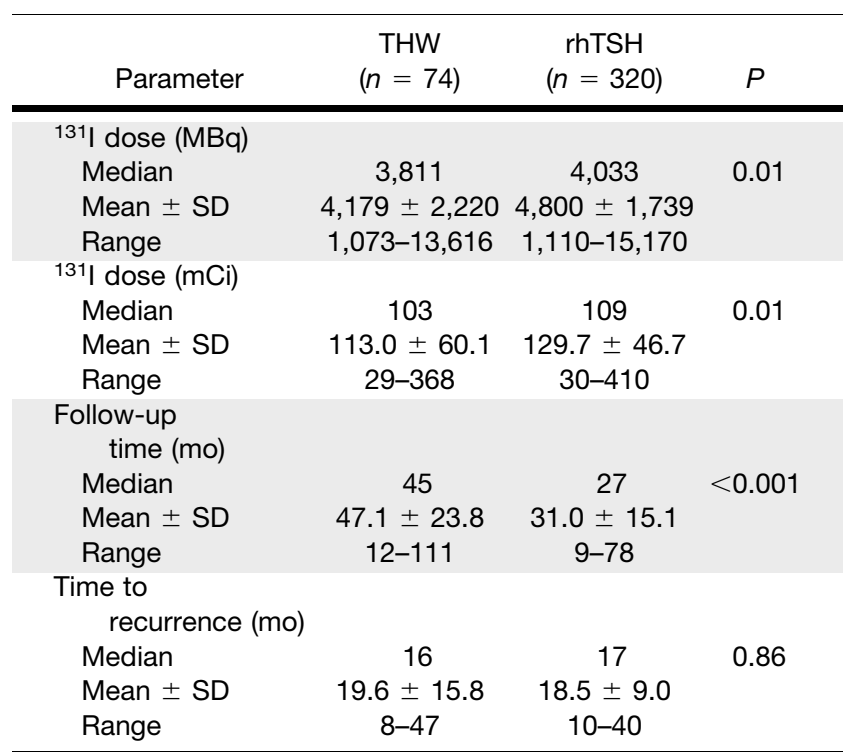

tional imaging), or known distant metastases at diagnosis. The fourth outcome, thyroid bed uptake only, was persistent uptake in the thyroid bed on the 1-y follow-up DxWBS with no other evidence of persistent disease (e.g., suppressed thyroglobulin level $<2 \mathrm{ng} / \mathrm{mL}$, stimulated thyroglobulin level $<10 \mathrm{ng} / \mathrm{mL}$, and negative ultrasound findings).

The cutoff values for suppressed and stimulated thyroglobulin in the NCED classification were based on our previous reports (17-19). We chose to use thyroglobulin values that reflect threshold values that could result in additional therapies as recommended in the recently published thyroid cancer guidelines (20) rather than using lower cutoffs to try to differentiate residual normal thyroid tissue from low-level persistent thyroid cancer. Unfortunately, there is no uniform agreement as to what suppressed or stimulated thyroglobulin value should be considered the gold standard for "no evidence of disease." However, for comparison purposes, we also analyzed the data using a definition of NCED based on suppressed thyroglobulin values of less than $1 \mathrm{ng} / \mathrm{mL}$ and stimulated thyroglobulin values of less than $2 \mathrm{ng} / \mathrm{mL}$.

Two nuclear medicine attending radiologists evaluated the DxWBS findings. The nuclear medicine readings were not performed in a masked fashion, although the physicians who read the films were unaware that a retrospective analysis of these data would occur.

\section{Laboratory and Pathology Studies}

Serum thyroglobulin was measured using the Dynotest-TgS (Brahms Inc.) immunoradiometric assay as previously described (2). The interassay precision for the thyroglobulin assay at 3.0 and $60.0 \mathrm{ng} / \mathrm{mL}$ was $3.2 \mathrm{ng} / \mathrm{mL}$ (8.7\% coefficient of variation) and $62.8 \mathrm{ng} / \mathrm{mL}$ ( $2.3 \%$ coefficient of variation), respectively. The functional sensitivity was $0.3 \mathrm{ng} / \mathrm{mL}$. Patients were excluded if interfering antithyroglobulin antibodies were present.

TSH was determined on an Advia Centaur (Bayer Corp.) using a 2-site sandwich immunoassay monitored by chemiluminometric technology. The assay exhibits a functional sensitivity of 0.019 $\mathrm{mIU} / \mathrm{L}$. The normal range for this assay is $0.37-4.42 \mathrm{mIU} / \mathrm{L}$. Free thyroxine (L-3,5,3',5'-tetraiodothyronine) was determined on an 


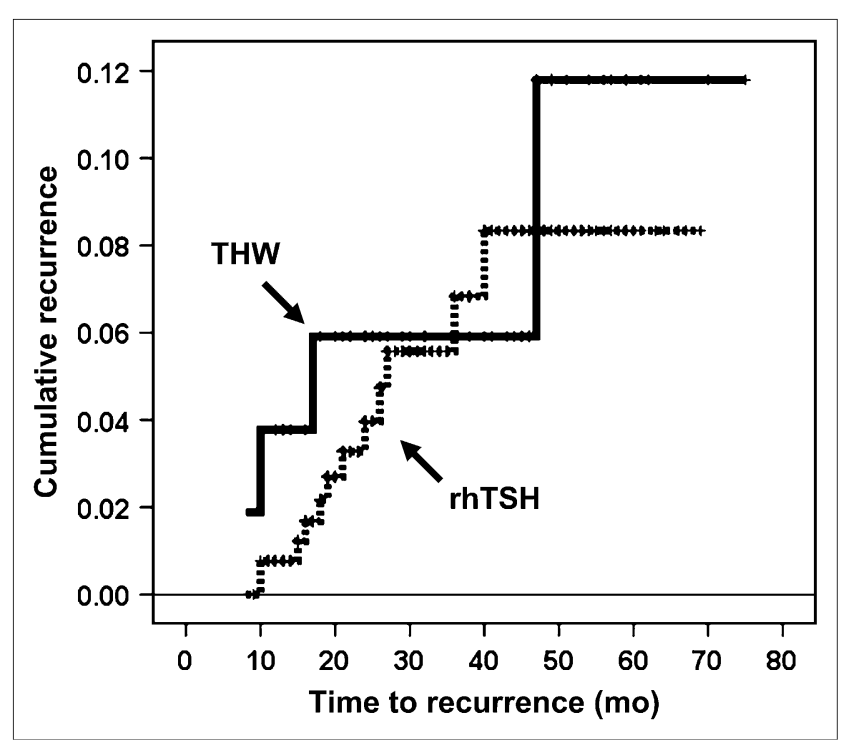

FIGURE 2. Kaplan-Meier curve showing time to recurrence in both rhTSH cohort and THW cohort. Longer time of follow-up for THW did not result in higher recurrence rates, because most recurrences in both groups were detected in first 24-36 mo after ablation.

Advia Centaur using a competitive immunoassay and direct chemiluminescent technology. The assay has a sensitivity of 0.1 $\mathrm{ng} / \mathrm{dL}$ and an interassay coefficient of variation of $3.03 \%$ at 1.1 $\mathrm{ng} / \mathrm{dL}$. The normal range for free thyroxine is $0.8-2.0 \mathrm{ng} / \mathrm{dL}$.

Surgical pathology slides from all patients were reviewed by MSKCC attending pathologists and confirmed to be differentiated thyroid cancer before any nuclear medicine studies were performed.

\section{Statistical Methods}

Data are presented as mean $\pm \mathrm{SD}$, or median (followed by range) when the distribution of data was skewed. SPSS 10.0 (SPSS Inc.) for Windows (Microsoft) was used for statistical analysis. Groups were compared for categoric data or frequency of events using the Pearson $\chi^{2}$ test and for continuous variables using the Student $t$ test. All tests were 2-sided, and values of $P$ less than 0.05 were considered statistically significant. A Kaplan-Meier table, estimating cumulative rates and time of clinical recurrence, was used to summarize the follow-up experience in the patient population.

\section{RESULTS}

\section{Patient and Tumor Characteristics}

The median age was higher for patients in the rhTSH group than for those in the THW group (46.5 y [18-83 y] and 44.0 y [6-81 y], respectively; $P=0.03$ ). The femaleto-male ratio was slightly higher in the rhTSH group, but the difference was not statistically significant $(P=0.43)$. No statistically significant difference was found in cancer histology between the study groups $(P=0.14)$. Tumor size, lymph node involvement, and the frequency of distant metastases did not differ significantly between groups. No difference was found in the overall American Joint Committee on Cancer, sixth edition (AJCC6), stage of disease between the study groups $(P=0.85)$ (Table 1$)$.

\section{Nuclear Medicine and Follow-up Time}

Patients in the rhTSH group received slightly more ${ }^{131} \mathrm{I}$ for RRA (median, 4,033 MBq [109 $\mathrm{mCi}]$ ) than did those in the THW group (median, 3,811 MBq [103 $\mathrm{mCi}])(P=$ 0.01) (Table 2). The mean follow-up time of the overall study population was $34 \pm 18$ mo (median, 29 mo; range, 9-111 mo), and the overall time from ablation to recurrence was $19 \pm 11$ mo (median, $16 \mathrm{mo}$; range, $8-47 \mathrm{mo}$ ). The study follow-up time for the THW group was significantly longer than that for the rhTSH group ( $47 \pm 24$ and $31 \pm 15$ mo, respectively; $P<0.001$ ). However, the time to recurrence was similar in both groups (THW, $19.6 \pm 15.8 \mathrm{mo}$, and rhTSH, $18.5 \pm 8.9$ mo; $P=0.86$ ) (Fig. 2). As can be seen from Figure 2, nearly all recurrences in both cohorts were detected within the first 40 mo of follow-up, with only 1 additional recurrence detected in the THW group during the time of extended follow-up, making it unlikely that the longer follow-up time in the THW group contributed disproportionately to the recurrence rate when compared with the rhTSH cohort.

\section{Surrogate Markers (Thyroglobulin Endpoints and Follow-up DxWBS)}

Thyroid Bed Uptake on Follow-up DxWBS. In our study population, 291 of the 394 patients underwent follow-up rhTSH DxWBS 12-18 mo after the RRA done at MSKCC. Based on either no visible 48-h thyroid bed uptake or, if visible, less than $0.1 \%$ uptake, the rate of successful ablation on 1-y follow-up DxWBS was $94.5 \%$ in the rhTSH-assisted ablation group and $90.1 \%$ in the THW group $(P=0.35)$ (Table 3$)$.

Serum Thyroglobulin. The patients in the rhTSH group had a significantly lower median suppressed serum thyroglobulin level at the 6-mo follow-up visit as than did the THW group $(0.6$ vs. $1 \mathrm{ng} / \mathrm{mL}, P=0.003)$. The groups did not significantly

TABLE 3

Thyroid Bed Uptake on Follow-up DxWBS

\begin{tabular}{lccc}
\hline Parameter & Negative 48-h TB uptake & 48-h TB uptake of 0\%-0.1\% & 48-h TB uptake $\geq 0.1 \%$ \\
\hline THW $(n=71)$ & $76.0 \%(54)$ & $14.1 \%(10)$ & $9.9 \%(7)$ \\
rhTSH $(n=220)$ & $82.7 \%(182)$ & $11.8 \%(26)$ & $5.5 \%(12)$ \\
Total $(n=291)$ & $81.1 \%(236)$ & $12.4 \%(36)$ & $6.5 \%(19)$ \\
& & & \\
\hline TB $=$ thyroid bed. & & & \\
\hline
\end{tabular}


TABLE 4

Serum Thyroglobulin at Follow-up

\begin{tabular}{|c|c|c|c|}
\hline Parameter & THW & rhTSH & $P$ \\
\hline \multicolumn{4}{|l|}{ Suppressed thyroglobulin $(\mathrm{ng} / \mathrm{mL})$} \\
\hline \multicolumn{4}{|l|}{$6 \mathrm{mo}$} \\
\hline Median & 1.0 & 0.6 & 0.003 \\
\hline Mean $\pm S D$ & $44.2 \pm 213.9$ & $5.0 \pm 27.5$ & \\
\hline Range & $0-1,296$ & 0-288 & \\
\hline \multicolumn{4}{|l|}{$12-18 \mathrm{mo}$} \\
\hline Median & 0.8 & 0.6 & 0.62 \\
\hline Mean $\pm S D$ & $4.9 \pm 13.7$ & $138.4 \pm 2299.5$ & \\
\hline Range & $0-78$ & $0-40,800$ & \\
\hline \multicolumn{4}{|l|}{ Stimulated thyroglobulin $(\mathrm{ng} / \mathrm{mL})$} \\
\hline \multicolumn{4}{|l|}{$12-18 \mathrm{mo}$} \\
\hline Median & 1.0 & 0.8 & 0.59 \\
\hline Mean $\pm \mathrm{SD}$ & $26.2 \pm 119.1$ & $272.3 \pm 3,648.5$ & \\
\hline Range & 0-900 & $0-56,000$ & \\
\hline \multicolumn{4}{|c|}{ Suppressed thyroglobulin $(\mathrm{ng} / \mathrm{mL})$ at final follow-up } \\
\hline Median & 0.6 & 0.6 & 0.61 \\
\hline Mean $\pm S D$ & $44.4 \pm 328.7$ & $2060.1 \pm 33736.7$ & \\
\hline Range & $0-2,800$ & $0-598,000$ & \\
\hline
\end{tabular}

differ with respect to suppressed thyroglobulin values at 12-18 mo after RRA, rhTSH-stimulated thyroglobulin values 12-18 mo after RRA, or suppressed thyroglobulin at the time of the final follow-up evaluation (Table 4).

\section{Clinical Outcomes}

Clinical outcomes were assessed a median of 29 mo after RRA. Compared with the 74 patients prepared with THW, the 320 patients who underwent rhTSH-assisted RRA were slightly more likely to be NCED (76\% rhTSH vs. $62 \%$ THW, $P=0.1$ ) and slightly less likely to have persistent disease $(16 \%$ rhTSH vs. $24 \%$ THW, $P=0.1$ ), although these differences did not reach statistical significance. The 2 cohorts had similar rates of clinically evident disease recurrence (4\% rhTSH vs. $7 \%$ THW, $P=0.1$ ) and residual thyroid bed uptake without other evidence of persistent disease (4\% rhTSH vs. $7 \%$ THW, $P=0.1$ ) (Table 5).

In all, 17 patients had clinical evidence of disease recurrence (5/74 THW patients and 12/320 rhTSH patients). No significant differences in sex, age at time of ablation, administered ${ }^{131} \mathrm{I}$ activity, tumor multifocality, AJCC6 stage, or histology of the primary tumor was seen when the 17 patients in whom clinically evident disease recurred were compared with the 290 patients who had no clinical evidence of recurrence. However, cervical lymph node metastases were detected in $76 \%$ (13/17) of the patients in whom a clinical recurrence developed, compared with $41 \%(119 / 290)$ of the patients who had NCED at the final follow-up $(P=0.005)$.

In these 17 patients, the most common site of recurrence in both groups was the cervical lymph nodes $(4 / 5$, or $80 \%$, of TWH patients and 10/12, or $83 \%$, of rhTSH patients), detected by a wide range of modalities including neck palpation, neck ultrasound, DxWBS, or ${ }^{18}$ F-FDG PET. New lung metastases were detected in $1(20 \%)$ of 5 patients of the THW cohort and $1(8.3 \%)$ of 12 patients of the rhTSH cohort by chest CT or ${ }^{18}$ F-FDG PET. One patient (8.3\%) of the TWH cohort was classified as having recurrent disease on the basis of a rising serum thyroglobulin level without structural evidence of disease on neck ultrasound, DxWBS, and ${ }^{18}$ F-FDG PET.

\section{Secondary Analysis of Treatment Outcomes with Thyroglobulin Cutoffs of Less Than $1 \mathrm{ng} / \mathrm{mL}$ with Suppressed TSH and Less Than $2 \mathrm{ng} / \mathrm{mL}$ After rhTSH Stimulation}

For the secondary analysis of treatment outcomes in our study population, we also used thyroglobulin cutoffs of less than $1 \mathrm{ng} / \mathrm{mL}$ during levothyroxine suppression and less than $2 \mathrm{ng} / \mathrm{mL}$ after $\mathrm{rhTSH}$ stimulation to more strictly

TABLE 5

Clinical Outcomes a Median of 2.5 Years After Initial Ablation Using Suppressed Thyroglobulin of Less Than $2 \mathrm{ng} / \mathrm{mL}$ and Stimulated Thyroglobulin of Less Than $10 \mathrm{ng} / \mathrm{mL}$ to Define NCED

\begin{tabular}{|c|c|c|c|c|c|}
\hline Parameter & NCED & Clinical recurrence & Persistent disease & TB uptake Only & $P$ \\
\hline $\mathrm{THW}(n=74)$ & $62.2 \%(46)$ & $6.8 \%(5)$ & $24.3 \%(18)$ & $6.8 \%(5)$ & 0.10 \\
\hline $\operatorname{rhTSH}(n=320)$ & $76.3 \%(244)$ & $3.8 \%(12)$ & $15.9 \%(51)$ & $4.1 \%(13)$ & \\
\hline Total $(n=394)$ & $73.6 \%(290)$ & $4.3 \%(17)$ & $17.5 \%(69)$ & $4.6 \%(18)$ & \\
\hline
\end{tabular}


TABLE 6

Clinical Outcomes a Median of 2.5 Years After Initial Ablation Using Suppressed Thyroglobulin of Less Than $1 \mathrm{ng} / \mathrm{mL}$ and Stimulated Thyroglobulin of Less Than $2 \mathrm{ng} / \mathrm{mL}$ to Define NCED

\begin{tabular}{lcccc}
\hline Parameter & NCED & Clinical recurrence & Persistent disease & TB uptake Only \\
\hline THW $(n=74)$ & $55.4 \%(41)$ & $6.8 \%(5)$ & $32.4 \%(24)$ & $5.4 \%(4)$ \\
rhTSH $(n=320)$ & $73.8 \%(236)$ & $3.8 \%(12)$ & $19.4 \%(62)$ & $3.1 \%(10)$ \\
Total $(n=394)$ & $70.3 \%(277)$ & $4.3 \%(17)$ & $21.8 \%(86)$ & $3.6 \%(14)$ \\
& & & & \\
\hline TB $=$ thyroid bed. & & & & \\
\hline
\end{tabular}

define NCED (Table 6). As would be expected, some NCED cases were reclassified as persistent disease using these lower cutoffs. However, the clinical outcomes using these thyroglobulin cutoffs did not affect the rates of clinical recurrence and only slightly decreased the outcome rates in the "thyroid bed uptake only" group.

\section{Secondary Analysis Based on Initial Risk Stratification}

Because the approval of rhTSH as an adjunct for RRA in the United States was specifically for patients without evidence of metastatic disease at diagnosis, we reanalyzed our outcome data excluding those patients known to have a distant metastasis at diagnosis (Table 7). As would be expected, excluding patients with distant metastases at diagnosis resulted in a decrease in the percentage of patients with persistent disease but had essentially no impact on clinical recurrence rates. If we use the European approach and restrict the analysis to low-risk patients (AJCC6 stages I and II without distant metastases), the risk of clinical recurrence declines to $2 \%$ in both the THW and the rhTSH cohorts (Table 7).

\section{DISCUSSION}

This study demonstrated no significant difference in short-term recurrence rates after RRA in thyroid cancer patients prepared either by administering rhTSH in the euthyroid state or by withholding levothyroxine for endogenous TSH stimulation. Furthermore, when the definition of NCED included a suppressed thyroglobulin level of less than $1 \mathrm{ng} / \mathrm{mL}$ and a stimulated thyroglobulin level of less than $2 \mathrm{ng} / \mathrm{mL}$, rhTSH-assisted RRA was associated with significantly higher rates of NCED and significantly lower rates of persistent disease than was RRA after THW.

Our data confirm previous reports of highly successful radioactive ablation of iodine remnants after rhTSH preparation and administration of activities of approximately $3,700 \mathrm{MBq}(100 \mathrm{mCi})(1,2,14-16)$. As with these previous publications, rhTSH stimulation achieved a high rate of successful ablation of all visible uptake in the thyroid bed on follow-up diagnostic whole-body radioactive iodine scans. The more rapid whole-body clearance of radioactive iodine in the rhTSH subjects also offers the potential benefit of lower whole-body radiation exposure from similar administered activities of radioactive iodine $(1,6)$.

This study had several limitations. It was a nonrandomized, uncontrolled retrospective chart-review study, with a selection bias of patients referred to MSKCC for the treatment of their thyroid cancer. The follow-up period was relatively short (median, $2.5 \mathrm{y}$ ), making it impossible to rule out a difference in the rates of late recurrence, which could still develop many years after RRA. In addition, the short follow-up period might have overestimated the number of patients with "persistent disease," because in many patients, low-level serum thyroglobulin values continue to decline with observation alone for as long as 5-10 y after initial therapy (21). It is possible that the percentage of patients with persistent disease would have been lower if a longer follow-up period had been available.

\section{TABLE 7}

Clinical Outcomes, Based on Initial Risk Stratification, a Median of 2.5 Years After Initial Ablation Using Suppressed Thyroglobulin of Less Than $1 \mathrm{ng} / \mathrm{mL}$ and Stimulated Thyroglobulin of Less Than $2 \mathrm{ng} / \mathrm{mL}$ to Define NCED

\begin{tabular}{|c|c|c|c|c|c|}
\hline Parameter & NCED & Clinical recurrence & Persistent disease & TB uptake only & $P$ \\
\hline \multicolumn{6}{|c|}{ Excluding distant metastases at diagnosis (M1) } \\
\hline $\operatorname{THW}(n=69)$ & $73 \%(50)$ & $6 \%(4)$ & $17 \%(12)$ & $4 \%(3)$ & NS \\
\hline $\operatorname{rhTSH}(n=302)$ & $82 \%(246)$ & $4 \%(12)$ & $11 \%(32)$ & $4 \%(12)$ & \\
\hline Total $(n=394)$ & $80 \%(296)$ & $4 \%(16)$ & $12 \%(44)$ & $4 \%(15)$ & \\
\hline \multicolumn{6}{|c|}{ AJCC6 I and II without distant metastases } \\
\hline THW $(n=49)$ & $78 \%(38)$ & $2 \%(1)$ & $16 \%(8)$ & $4 \%(2)$ & NS \\
\hline $\operatorname{rhTSH}(n=195)$ & $84 \%(163)$ & $2 \%(4)$ & $11 \%(22)$ & $3 \%(6)$ & \\
\hline Total $(n=244)$ & $82 \%(201)$ & $2 \%(5)$ & $12 \%(30)$ & $3 \%(8)$ & \\
\hline
\end{tabular}

$\mathrm{TB}=$ thyroid bed; NS $=$ not statistically significant. 
Even though the primary variable that biased patients toward selection of THW for RRA was the lack of an option for rhTSH (before rhTSH was commercially available), it is likely that patients perceived to be at high risk for recurrence may have been preferentially selected for THW over rhTSH preparation, especially in the earliest patients offered rhTSH-assisted RRA. Despite careful retrospective analysis of the data, we could not identify significant differences in major variables such as thyroid cancer histology, tumor size, lymph node involvement, frequency of distant metastases, or AJCC6 stage of disease between patients selected for THW and patients selected for an rhTSH preparation for RRA. The only clinical difference detected was that the rhTSH group was slightly older than the THW group ( $48 \pm 15 \mathrm{y}$ and $44 \pm 15 \mathrm{y}$, respectively; $P=$ 0.03). However, a subtle selection bias on the part of the patient or treating physician cannot be completely ruled out.

Finally, the longer follow-up time for the THW group complicates the comparison $(47 \pm 24$ mo for THW vs. $31 \pm 15$ mo for rhTSH, $P<0.001)$. Because rhTSH was not yet commercially available in 1997 and 1998, all patients treated at that time were by necessity prepared with THW. With the approval of the Food and Drug Administration of the diagnostic use of rhTSH in December 1998, some clinicians at our medical center started offering thyroid remnant ablation after preparation with rhTSH while the patients were receiving thyroid hormone suppressive therapy. Therefore, the study follow-up time was longer for the THW group than for the rhTSH group. However, despite the intergroup difference in the study follow-up time, the time to thyroid cancer recurrence after RRA was similar in the 2 study groups (THW, $20 \pm 16 \mathrm{mo}$, and rhTSH, $19 \pm 9 \mathrm{mo} ; P=0.86$ ). Therefore, it does not appear that the slightly higher recurrence rate in the THW group was due to the longer duration of follow-up; most recurrences were detected relatively soon after RRA in both groups. Obviously, much longer studies will be required to define the long-term recurrence rates in these cohorts; however, our results are similar to data previously reported by Schlumberger and Pacini (22), in which $80 \%$ of recurrences were detected within the first $3 \mathrm{y}$ of follow-up.

\section{CONCLUSION}

Our study findings demonstrate that rhTSH-assisted RRA is associated with rates of persistent disease and clinically evident recurrence that are similar to those for traditional THW therapy. In light of these data, the use of rhTSH for postthyroidectomy ${ }^{131}$ I RRA represents a safe and effective option for the postoperative management of patients with thyroid cancer. The choice of preparation for RRA (THW vs. rhTSH) should be made on the basis of the patient's quality of life and the "cost" of hypothyroidism versus the cost of rhTSH, and not on the likelihood of a complete ablation or short-term recurrence rates, which appear to be similar for these 2 methods of preparation.

\section{REFERENCES}

1. Luster M, Lippi F, Jarzab B, et al. rhTSH-aided radioiodine ablation and treatment of differentiated thyroid carcinoma: a comprehensive review. Endocr Relat Cancer. 2005;12:49-64.

2. Robbins RJ, Larson SM, Sinha N, et al. A retrospective review of the effectiveness of recombinant human TSH as a preparation for radioiodine thyroid remnant ablation. J Nucl Med. 2002;43:1482-1488.

3. Schlumberger MJ. Papillary and follicular thyroid carcinoma. $N$ Engl J Med. 1998;338:297-306.

4. Luster M, Felbinger R, Dietlein M, Reiners C. Thyroid hormone withdrawal in patients with differentiated thyroid carcinoma: a one hundred thirty-patient pilot survey on consequences of hypothyroidism and a pharmacoeconomic comparison to recombinant thyrotropin administration. Thyroid. 2005;15:1147-1155.

5. Sawka AM, Thephamongkhol K, Brouwers M, Thabane L, Browman G, Gerstein HC. Clinical review 170: a systematic review and metaanalysis of the effectiveness of radioactive iodine remnant ablation for well-differentiated thyroid cancer. J Clin Endocrinol Metab. 2004;89:3668-3676.

6. Robbins RJ, Robbins AK. Clinical review 156: recombinant human thyrotropin and thyroid cancer management. J Clin Endocrinol Metab. 2003;88: 1933-1938.

7. Schlumberger M, Pacini F, Wiersinga WM, et al. Follow-up and management of differentiated thyroid carcinoma: a European perspective in clinical practice. Eur J Endocrinol. 2004;151:539-548.

8. Sweeney DC, Johnston GS. Radioiodine therapy for thyroid cancer. Endocrinol Metab Clin North Am. 1995;24:803-839.

9. Dow KH, Ferrell BR, Anello C. Quality-of-life changes in patients with thyroid cancer after withdrawal of thyroid hormone therapy. Thyroid. 1997;7:613-619.

10. Schroeder PR, Haugen BR, Pacini F, et al. A comparison of short-term changes in health-related quality of life in thyroid carcinoma patients undergoing diagnostic evaluation with recombinant human thyrotropin compared with thyroid hormone withdrawal. J Clin Endocrinol Metab. 2006;91:878-884.

11. Haugen BR, Pacini F, Reiners C, et al. A comparison of recombinant human thyrotropin and thyroid hormone withdrawal for the detection of thyroid remnant or cancer. J Clin Endocrinol Metab. 1999;84:3877-3885.

12. Ladenson PW, Braverman LE, Mazzaferri EL, et al. Comparison of administration of recombinant human thyrotropin with withdrawal of thyroid hormone for radioactive iodine scanning in patients with thyroid carcinoma. $N$ Engl J Med. 1997;337:888-896.

13. Robbins RJ, Tuttle RM, Sharaf RN, et al. Preparation by recombinant human thyrotropin or thyroid hormone withdrawal are comparable for the detection of residual differentiated thyroid carcinoma. J Clin Endocrinol Metab. 2001;86: 619-625.

14. Pacini F, Ladenson PW, Schlumberger M, et al. Radioiodine ablation of thyroid remnants after preparation with recombinant human thyrotropin in differentiated thyroid carcinoma: results of an international, randomized, controlled study. J Clin Endocrinol Metab. 2006;91:926-932.

15. Barbaro D, Boni G, Meucci G, et al. Radioiodine treatment with $30 \mathrm{mCi}$ after recombinant human thyrotropin stimulation in thyroid cancer: effectiveness for postsurgical remnants ablation and possible role of iodine content in L-thyroxine in the outcome of ablation. J Clin Endocrinol Metab. 2003;88:4110-4115.

16. Pacini F, Molinaro E, Castagna MG, et al. Ablation of thyroid residues with 30 $\mathrm{mCi}{ }^{131} \mathrm{I}$ : a comparison in thyroid cancer patients prepared with recombinant human TSH or thyroid hormone withdrawal. J Clin Endocrinol Metab. 2002;87: 4063-4068.

17. Mazzaferri EL, Robbins RJ, Spencer CA, et al. A consensus report of the role of serum thyroglobulin as a monitoring method for low-risk patients with papillary thyroid carcinoma. J Clin Endocrinol Metab. 2003;88:1433-1441.

18. Robbins RJ, Chon JT, Fleisher M, Larson SM, Tuttle RM. Is the serum thyroglobulin response to recombinant human thyrotropin sufficient, by itself, to monitor for residual thyroid carcinoma? J Clin Endocrinol Metab. 2002;87: 3242-3247.

19. Robbins RJ, Srivastava S, Shaha A, et al. Factors influencing the basal and recombinant human thyrotropin-stimulated serum thyroglobulin in patients with metastatic thyroid carcinoma. J Clin Endocrinol Metab. 2004;89:6010-6016.

20. Cooper DS, Doherty GM, Haugen BR, et al. Management guidelines for patients with thyroid nodules and differentiated thyroid cancer. Thyroid. 2006;16: 109-142.

21. Pacini F, Agate L, Elisei R, et al. Outcome of differentiated thyroid cancer with detectable serum $\mathrm{Tg}$ and negative diagnostic ${ }^{131} \mathrm{I}$ whole body scan: comparison of patients treated with high ${ }^{131} \mathrm{I}$ activities versus untreated patients. J Clin Endocrinol Metab. 2001;86:4092-4097.

22. Schlumberger M, Pacini F. Thyroid Tumors. 2nd ed. Paris, France: Nucleon; 2003. 